\title{
Comparative Analysis of Surface Layer Glycoproteins and Genes Involved in Protein Glycosylation in the Genus Haloferax
}

\author{
Yarden Shalev ${ }^{1}$ (D) , Shannon M. Soucy ${ }^{2}$, R. Thane Papke ${ }^{2}$, J. Peter Gogarten ${ }^{3}{ }^{(\mathbb{D})}$, Jerry Eichler ${ }^{4}(\mathbb{D})$ \\ and Uri Gophna ${ }^{1, *}$ \\ 1 School of Molecular and Cell Biology and Biotechnology, George S. Wise Faculty of Life Sciences, \\ Tel Aviv University, Tel Aviv 69978, Israel; yardenshalev@mail.tau.ac.il \\ 2 Department of Molecular and Cell Biology, University of Connecticut, Storrs, CT 06269, USA; \\ shannon.soucy@uconn.edu (S.M.S.); thane@uconn.edu (R.T.P.) \\ 3 Institute for Systems Genomics, University of Connecticut, Storrs, CT 06269, USA; gogarten@uconn.edu \\ 4 Department of Life Sciences, Ben Gurion University of the Negev, Beersheva 8410501, Israel; \\ jeichler@bgu.ac.il \\ * Correspondence: urigo@tau.ac.il; Tel.: +972-3-640-9988
}

Received: 29 January 2018; Accepted: 9 March 2018; Published: 20 March 2018

\begin{abstract}
Within the Haloferax genus, both the surface (S)-layer protein, and the glycans that can decorate it, vary between species, which can potentially result in many different surface types, analogous to bacterial serotypes. This variation may mediate phenotypes, such as sensitivity to different viruses and mating preferences. Here, we describe S-layer glycoproteins found in multiple Haloferax strains and perform comparative genomics analyses of major and alternative glycosylation clusters of isolates from two coastal sites. We analyze the phylogeny of individual glycosylation genes and demonstrate that while the major glycosylation cluster tends to be conserved among closely related strains, the alternative cluster is highly variable. Thus, geographically- and genetically-related strains may exhibit diverse surface structures to such an extent that no two isolates present an identical surface profile.
\end{abstract}

Keywords: glycosylation; halophilic archaea; horizontal gene transfer; lateral gene transfer; mating; recombination; S-layer

\section{Introduction}

The prokaryotic cell envelope provides archaeal and bacterial cells with a protective coat that resists environmental stressors both abiotic and biotic-namely viruses and toxins secreted by competing cells. In archaea, the surface layer (S-layer) is generally composed of a single protein that is always glycosylated [1]. N-glycosylation-the covalent attachment of glycans to select target asparagine residues in proteins-is thought to be one of the most common post-translational modifications of archaeal cell surface proteins, including S-layer glycoproteins, as well as flagelins [2] and pilins [3]. Archaeal $\mathrm{N}$-linked glycans are richly diverse in composition and structure [4,5] and accordingly, archaeal $\mathrm{N}$-glycosylation gene pathways show considerable variation in gene content, sharing only a few common components.

The N-glycosylation pathways of the halophilic archaeon Haloferax volcanii have been intensively studied and are relatively well-understood. $H$. volcanii contains two $N$-glycosylation pathways - a major pathway which is functional at all concentrations of salt tested and an alternative glycosylation pathway which is only recruited at lower salinity-with each pathway generating its own distinct glycan modification [6]. When relying on the general $N$-glycosylation pathway, the $H$. volcanii 
S-layer glycoprotein is modified by a pentasaccharide in a process whereby the glycosyltransferases AglJ, AglG, AglI and AlgE sequentially add the first four sugars of the $N$-linked pentasaccharide to a common dolichol phosphate carrier [7-10]. After the lipid-linked tetrasaccharide has been translocated across the membrane, the glycan is delivered to selected S-layer glycoprotein Asn-residues by AglB, the archaeal oligosaccharyltransferase [11,12]. The final sugar of the pentasaccharide is added to a distinct dolichol phosphate carrier on the cytoplasmic face of the membrane by the glycosyltransferase AgID [7,9]. The dolichol phosphate-bound sugar is then delivered across the membrane to face the exterior of the cell in a process involving AglR, at which point the sugar is transferred to the Asn-linked tetrasaccharide by AglS [9,13-16]. Other Agl proteins serve various sugar-processing roles that contribute to pentasaccharide assembly. AglF is a glucose-1-phosphate uridyltransferase, AglM is a UDPglucose dehydrogenase, AglP is a methyltransferase and AglQ is an isomerase [8,17-19]. All the genes encoding proteins known to participate in the assembly and attachment of a pentasaccharide to selected Asn residues of $\mathrm{N}$-glycosylated proteins in $\mathrm{H}$. volcanii are located within the same gene cluster beginning at the agl gene and extending to $a g l M$, with the exception of aglD that is found outside this cluster [20].

The proteins responsible for assembly of the pentasaccharide $N$-linked glycan are not involved in the biosynthesis of the low salt glycan, a tetrasaccharide of distinct composition. agl5-agl15 have been identified as comprising an alternative $\mathrm{N}$-glycosylation pathway. Agl5 and Ag16 are implicated, in addition to a hexose to dolichol phosphate, while Agl7 contributes to the sulfation of this lipid-linked sugar. Agl8 and Agl9 are involved in the addition of a hexose to disaccharide-charged dolichol phosphate. Agl10-14 are involved in the subsequent addition of a rhamnose to the dolichol phosphate-bound trisaccharide, while Agl15 is predicted to serve as a flippase, mediating the translocation of the low salt tetrasaccharide-charged dolichol phosphate across the membrane [21].

Given that archaeal $N$-linked glycans can vary greatly in composition and structure between species and that different species within the same genus can have different glycosylation clusters [22], it is highly likely that in the environment, different, closely-related haloarchaeal strains may present a wide assortment of different surface decorations that can modify the different S-layer glycoproteins in each species. Here, we performed genomics analysis on multiple Haloferax strains isolated from two relatively close coastal sites by comparing their genomes to those of previously isolated named Haloferax species to investigate the diversity and evolution of genes that shape the surface of haloarchaeal cells. We used multiple phylogenetic analyses to show that while the S-layer glycoprotein appears to be mostly vertically inherited, lateral gene transfer can impact glycosylation genes even when gene organization is highly conserved. We also identified a novel major S-layer glycoprotein and validated it biochemically.

\section{Materials and Methods}

\subsection{Sample Collection and $16 S$ rRNA/polB Gene Sequencing}

Stagnant seawater or dry salt samples were collected from four tidal/spray pools at two rocky shores along Israel's Mediterranean coastline (Atlit ( $32^{\circ} 42^{\prime} 37.3^{\prime \prime} \mathrm{N} 34^{\circ} 56^{\prime} 32.0^{\prime \prime}$ E) and Michmoret $\left(32^{\circ} 24^{\prime} 23.8^{\prime \prime} \mathrm{N} 34^{\circ} 52^{\prime} 05.2^{\prime \prime} \mathrm{E}\right)$ ). Five milliliters of seawater from each pool were spread onto a yeast extract, peptone and casmino acids (YPC) plate containing ampicillin and incubated at $42{ }^{\circ} \mathrm{C}$ until colonies appeared. Dry salt samples were dissolved in sterile seawater before spreading on plates. Colonies with typical Haloferax coloring and shape were further examined with 16S rRNA gene PCR using Halobacteriales-specific 16S rRNA gene primers 287F and 958R [23]. The <600 bp amplicon was sequenced by ABI 3730XL sequencers at MCLAB DNA Sequencing Services (San Francisco, CA, USA). Colonies that proved to belong to the Haloferax genus had their whole genome sequenced using Illumina MiSeq (Illumina, San Diego, CA, USA) $2 \times 250$ paired-end reads at the Weizmann Institute genomics facility (Weizmann Institute of Science, Rehovot, Israel). Raw reads were first trimmed with Cutadapt v1.9.1 [24] to remove adaptor sequences and bases with a Phred score lower than 20. 
Genomes were assembled using SPAdes v3.7.0 [25] with kmer sizes 21, 33, 55, 77, 99 and 127. Assembly quality was checked using Quast v2.3 [26] and coding sequences and annotations were predicted using Prokka v1.11 [27], ignoring contigs that were shorter than 200 base pairs.

\subsection{Genomic DNA Extraction by Spooling}

Cultures of Haloferax colonies were grown to $2.0 \mathrm{OD}_{600}$ under shaking conditions at $45^{\circ} \mathrm{C}$ for two nights. $1.5 \mathrm{~mL}$ of culture was centrifuged for $5 \mathrm{~min}$ at $6000 \times \mathrm{g}$, then resuspended in $200 \mu \mathrm{L}$ of ST buffer $(1 \mathrm{M} \mathrm{NaCl}, 20 \mathrm{mM}$ Tris- $\mathrm{HCl})$ and $200 \mu \mathrm{L}$ of lysis solution (100 mM EDTA pH 8.0, 0.2\% SDS) is added. $1 \mathrm{~mL}$ of ethanol was added and the DNA spooled onto a glass capillary until liquid was homogeneous and clear. The DNA was washed 3 times by transferring the spooled DNA to a microcentrifuge tube with $1 \mathrm{~mL}$ of fresh ethanol and was then allowed to dry. The DNA was then solubilized in $250 \mu \mathrm{L}$ Tris EDTA (TE) buffer.

\subsection{Phylogenetic Analysis}

The protein and nucleotide sequences of AglB and RpoB1 from H. volcanii DS2 and H. Gibbonsii ATCC 33959 were retrieved from the Kyoto Encyclopedia of Genes and Genomes (KEGG) database [28]. The protein and nucleotide sequences of AglB and RpoB1 from H. lucentense DSM 14919 and H. Denitrificans ATCC 35960 were retrieved from the National Center for Biotechnology Information (NCBI) database. Gene and protein sequences of the Haloferax isolates were aligned using MAFFT [29]. Trees were constructed using maximum-likelihood as implemented in MEGA7 [30], with 100 bootstrap trials. The evolutionary history was inferred from the nucleotide sequences using the Maximum Likelihood method, based on the Tamura-Nei model [31], and in the case of the protein sequence AglB, the evolutionary history was inferred by using the Maximum Likelihood method based on the JTT matrix-based model [32]. The tree with the highest log likelihood is shown in all phylogeny figures. Initial tree(s) for heuristic searches were obtained automatically by applying Neighbor-Join and BioNJ algorithms to a matrix of pairwise distances, estimated using the Maximum Composite Likelihood (MCL) approach and then by selecting the topology with the superior log likelihood value.

\subsection{Estimation of the Significance of a Protein Sequence Alignment Using PRSS}

PRSS (protein sequence alignment significance) analyses was performed to assess homology through shuffling from pairwise sequence comparison [33,34].

\subsection{Protein Function Prediction}

Protein function predictions of genes in glycosylation clusters were performed with HHpred [35].

\subsection{Recombination Analysis}

Recombination analysis was performed using the Recombination Detection Program (RDP) v4, which uses multiple detection algorithms including the RDP Method [36], GENECOV [37], BootScan [38], MaxChi [39], Chimaera [40], SiScan [41] and 3Seq [42] to check for the presence of recombinant sequences [43]. Events were considered reliable only if at least four of these algorithms supported recombination.

\subsection{Average Nucleotide Identity Calculation}

The average nucleotide identity (ANI) calculator used [44] estimated the average nucleotide identity using reciprocal best hits (two-way ANI) between two genomic datasets, as calculated in [45].

\subsection{Culture Conditions}

H. volcanii cells were routinely grown (as described in Reference [46]) in a rich medium (Hv-YPC) containing (per liter) $144 \mathrm{~g}$ of $\mathrm{NaCl}, 21 \mathrm{~g}$ of $\mathrm{MgSO}_{4} \cdot 7 \mathrm{H}_{2} \mathrm{O}, 18 \mathrm{~g}$ of $\mathrm{MgCl}_{2} \cdot 6 \mathrm{H}_{2} \mathrm{O}, 4.2 \mathrm{~g}$ of $\mathrm{KCl}$ and $12 \mathrm{mM}$ 
Tris- $\mathrm{HCl}$ (pH 7.5). For solid media, agar (Difco, BD, NJ, USA) was added at a concentration of $15 \mathrm{~g}$ per liter and was dissolved by heating the medium on a hot plate. Yeast extract $(0.5 \%, \mathrm{wt} / \mathrm{vol}$; Difco), peptone (Bacto; $0.1 \%, \mathrm{wt} / \mathrm{vol}$ ) and casamino acids (Difco; $0.1 \%$, wt $/ \mathrm{vol}$ ) were added and the medium was autoclaved. After cooling, $\mathrm{CaCl}_{2}$ was added to a final concentration of $3 \mathrm{mM}$.

\subsection{Protein Sample Preparation}

Cultures of $H$. volcanii cells were grown to $1.0 \mathrm{OD}_{600}$ under shaking conditions at $45{ }^{\circ} \mathrm{C}$ overnight. To $100 \mu \mathrm{L}$ aliquots, $43 \mu \mathrm{L}$ of $50 \%$ Trichloroacetic acid (15\% final concentration) were added. Samples were incubated for $30 \mathrm{~min}$ on ice and then centrifuged at $10,000 \times \mathrm{g}$ for $15 \mathrm{~min}$ at $4{ }^{\circ} \mathrm{C}$. One $\mathrm{mL}$ of ice-cold acetone was added to the pellet, which was then centrifuged again at $10,000 \times g$ for $15 \mathrm{~min}$ at $4{ }^{\circ} \mathrm{C}$. The pellet was left to dry for $5 \mathrm{~min}$, after which time $30 \mu \mathrm{L}$ of $2 \times$ sample buffer was added. The samples underwent sonication for $1 \mathrm{~min}$ in a supersonic cleaner (model DG-1, M.R.C, Holon, Israel), heated for $5 \mathrm{~min}$ at $95^{\circ} \mathrm{C}$ and then separated by $6 \%$ SDS-PAGE.

\subsection{SDS-PAGE and Protein Detection}

SDS-PAGE was performed as described [47]. The gel was fixed in staining solution $(0.1 \%$ Coomassie Brilliant Blue R-250, 50\% methanol and 10\% acetic acid) for from an hour to overnight with gentle agitation, followed by destaining in $40 \%$ methanol and $10 \%$ acetic acid.

\subsection{Mass Spectrometry}

Mass spectrometry was performed by the Smoler Proteomics Center at the Technion, Israel Institute of Technology. Samples were digested by chymotrypsin and analyzed by LC-MS/MS on a Q-Exactive (Thermo, Waltham, MA, USA) apparatus. Samples were identified using Discoverer 1.4 with the Sequest search algorithm (Thermo, Waltham, MA, USA).

\section{Results}

\subsection{Phylogenetic Analysis of the Isolates Using the rpoB1 Gene and ANI}

Colonies with typical Haloferax morphology isolated from samples of stagnant seawater or dry salt samples from two rocky shores along Israel's Mediterranean coastline (Atlit and Michmoret) were further examined and subsequently the strains giving rise to these colonies, had their genomes sequenced (Table 1, see Section 2). The $16 \mathrm{~S}$ rRNA gene of all these isolates had over $99 \%$ identity to that of the $H$. volcanii type strain and consequently was deemed too conserved for resolving relatedness between isolates. Therefore, to determine the phylogenetic relationship between isolates, we used the rpoB1 gene (an RNA polymerase subunit encoded by conserved single-copy gene), which serves as a suitable phylogenetic marker for Halobacteriales [48]. The rpoB1 gene of $H$. gibbonsii was added to the analysis since isolates $4 \mathrm{~N}, 6 \mathrm{~N}, 10 \mathrm{~N}, 12 \mathrm{~N}, 16 \mathrm{~N}$ and $19 \mathrm{~N}$ (henceforth the $H$. gibbonsii clade) showed the highest sequence similarity to $H$. gibbonsii rpoB1. The rpoB1 tree (Figure 1) clustered into four main groups; isolates $4 \mathrm{~N}$ and $6 \mathrm{~N}$ clustered with $H$. gibbonsii, while $12 \mathrm{~N}$ was deep-branching. Isolates $10 \mathrm{~N}$, $16 \mathrm{~N}$ and $19 \mathrm{~N}$ grouped together and had identical rpoB1 sequences, whereas the rest of the isolates grouped with $H$. volcanii and $H$. lucentense. Isolates $24 \mathrm{~N}, 47 \mathrm{~N}$ and $48 \mathrm{~N}$ resembled H. lucentense and $H$. denitrificans, in terms of their main glycosylation pathway genes (see below, Figure 2) and therefore these species were added to the phylogenetic analysis.

Haloarchaea have been shown to be highly recombinogenic in nature $[49,50]$ and most transferred genes are incorporated into recipient genomes through homologous recombination [51]. Thus, single gene phylogenies should be accompanied by recombination detection. No recombination events between these rpoB1 sequences could be detected in the rpoB1 gene nucleotide sequence (Figure S1), possibly because this gene is not sufficiently variable to allow reliable detection. To avoid relying on a single gene marker for inference of genetic relatedness with an analysis of average nucleotide identity (ANI) of shared genes in these genomes [52] was performed. The ANI data were congruent with the 
rpoB1 results (Table S1), with $4 \mathrm{~N}$ and $6 \mathrm{~N}$ showing higher sequence similarity to $H$. gibbonsi than did isolates $10 \mathrm{~N}, 16 \mathrm{~N}$ and $19 \mathrm{~N}$ and $12 \mathrm{~N}$, which corresponded to a more distant lineage. In contrast to the rpoB1 phylogeny, $24 \mathrm{~N}$ appears to be closely related to $H$. volcanii, yet shares higher average nucleotide identity to $H$. lucentense.

Table 1. List of Haloferax isolates collected from four pools from two rocky shores along Israel's Mediterranean coastline (Atlit and Michmoret) and related Haloferax species added to the analysis due to their similarities to the isolates. ${ }^{*}$ Total length includes all replicons.

\begin{tabular}{|c|c|c|c|c|}
\hline Isolate Number & Place of Isolation & Number of Contigs over $1 \mathrm{Kbp}$ & GC Content (\%) & Total Length $(b p) *$ \\
\hline $6 \mathrm{~N}$ & Michmoret pool2 & 23 & 65.12 & $4,414,718$ \\
\hline $10 \mathrm{~N}$ & Michmoret pool2 & 54 & 65.2 & $4,278,547$ \\
\hline $16 \mathrm{~N}$ & Michmoret pool2 & 10 & 65.74 & $3,971,935$ \\
\hline $19 \mathrm{~N}$ & Atlit pool2 & 29 & 64.29 & $4,185,404$ \\
\hline $24 \mathrm{~N}$ & Atlit pool4 & 9 & 65.74 & $3,914,077$ \\
\hline Haloferax volcanii DS2 & Dead Sea & & 65 & $4,012,900$ \\
\hline Haloferax gibbonsii ATCC 33959 & Saltern, Rio de Janeiro & & 62.8 & $3,918,454$ \\
\hline Haloferax denitrificans ATCC 35960 & Saltern, California & & 66.3 & $3,825,970$ \\
\hline Haloferax lucentense DSM 14919 & Saltern, Spain & & 66.39 & $3,619,064$ \\
\hline
\end{tabular}

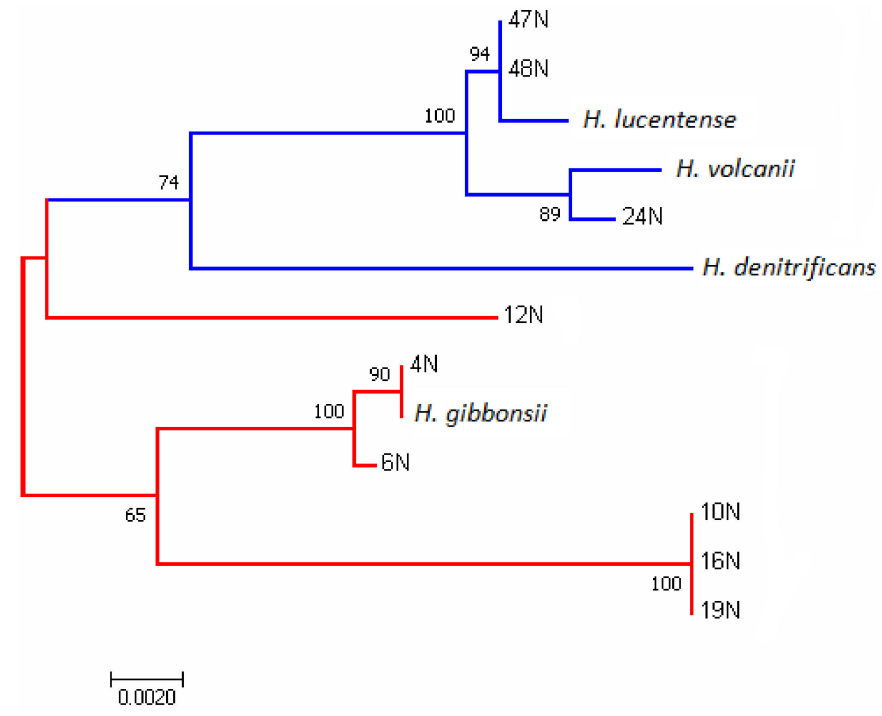

Figure 1. Molecular phylogenetic analysis of the rpoB1 gene by Maximum Likelihood. Red lines represent species and isolates with an S-layer glycoprotein corresponding to that of $H$. gibbonsii. Blue lines represent the species and isolates with an S-layer glycoprotein corresponding to the $\mathrm{H}$. volcanii S-layer glycoprotein (see below Section 3.2). The evolutionary history was inferred by using the Maximum Likelihood method based on the Tamura-Nei model [31]. The tree with the highest log likelihood (-3138.94) is shown. The percentage of trees in which the associated taxa clustered together is shown next to the branches. A discrete Gamma distribution was used to model evolutionary rate differences among sites $(5$ categories $(+G$, optimized shape parameter $=0.0500)$ ). The rate variation model allowed for some sites to be evolutionarily invariable $((+\mathrm{I}), 47.73 \%$ sites). The unrooted tree is drawn to scale, with branch lengths measured in the number of substitutions per site. The analysis involved 13 nucleotide sequences. Codon positions included were 1st +2 nd $+3 \mathrm{rd}$. All positions containing gaps and missing data were eliminated. A total of 1827 positions were in the final dataset. Evolutionary analyses were conducted in MEGA7 [30]. 


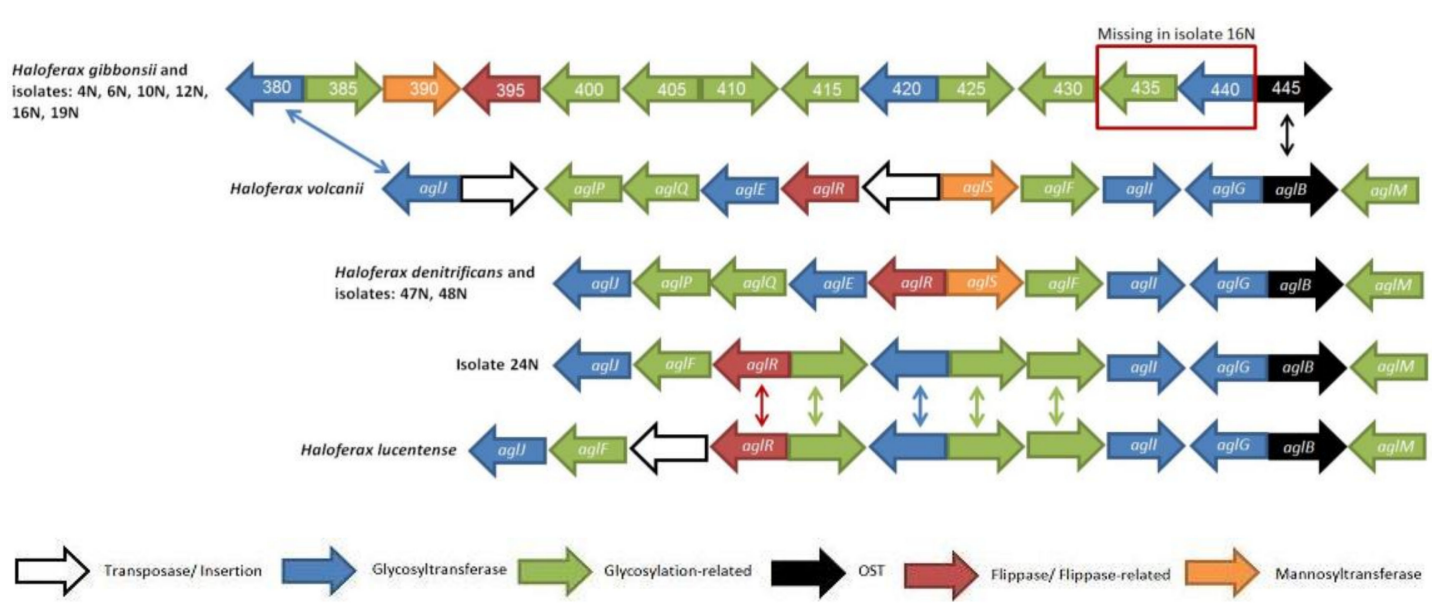

Figure 2. Schematic presentation of the aglB-based glycosylation clusters of four different Haloferax strains and the nine Haloferax isolates. The sizes of the genes are arbitrary. Arrows in between clusters indicate homology. The legend describes gene function according to the color scheme at the bottom. Protein function prediction was performed using HHpred [35]. Based on Figure 2 from Ref. [22].

\subsection{Two Distinct S-layer Glycoproteins Exist within the Closely-Related Haloferax Isolates}

The S-layer glycoprotein serves as the sole component of the protein layer surrounding $H$. volcanii cells and migrates on SDS-PAGE like a $205 \mathrm{kDa}$ polypeptide [53]. Even though all the isolates collected along Israel's Mediterranean coastline belonged to closely-related Haloferax lineages (see above), the strong high molecular weight SDS-PAGE bands representing putative S-layer glycoproteins in the isolates belonging to the $H$. gibonsii clade, as assigned on the basis of their rpoB phylogeny (4-19N), migrated slower than did their $H$. volcanii clade counterparts (including isolates $24-48 \mathrm{~N}$, Figure 1 ) suggesting differences in the sequences of their S-layer glycoproteins that may vary in molecular weight but also in their acidic amino acid content. We identified using InterPro [54] proteins from available haloarchaeal genomes that belonged to the IPR026458 family, having both a surface glycoprotein signal peptide (IPR026452) and a PGF-CTERM domain and an archaeal protein-sorting signal (IPR026371) (a C-terminal tripartite structure including a highly conserved proline-glycine-phenylalanine (PGF) motif). These proteins were then used to query the isolate genomes predicted proteins using BLAST [55]. As expected, the protein sequence acquired from $H$. gibbonsii (accession A0A0K1IRS6) had homologous matches in all the isolates from the $H$. gibbonsii clade but not to the S-layer glycoprotein present in $H$. volcanii DS2. The molecular weight of the predicted H. gibbonsii clade S-layer glycoprotein without covalently linked glycans was calculated to be $89.8 \mathrm{kDa}$ [56], which is similar to the molecular weight that of its $\mathrm{H}$. volcanii counterpart, which is $85.2 \mathrm{kDa}$ [42]. Following gel extraction of the predicted S-layer glycoprotein band (Figure 3) and chymotrypsin digestion of the protein, mass spectrometry confirmed that the slower migrating band of the H. gibbonsii clade indeed corresponded to A0A0K1IRS6, verifying that this is indeed a novel Haloferax S-layer glycoprotein. The fact that the two separate clades based on rpoB1 phylogeny express two distinct types of S-layer glycoproteins (Figure 1) implies that the genes encoding these proteins were not horizontally transferred between these clades [53] but rather that one of the clades has probably acquired its ancestral protein from a more distant lineage. A0A0K1IRS6 from $H$. gibbonsii and AAA72996.1 from $H$. volcanii showed only insignificant matches in the carboxy terminal part of the H. volcanii S-layer protein using BLASTP [55]; however, comparing the whole sequences in PRSS [33] revealed significant sequence similarity (using a PAM 400 matrix resulted in a $z$-value of 181 and an $\mathrm{E}(1)$ value of $2.7 \times 10^{-8}$ ). This suggests that the two types of S-layer proteins are divergent homologs. Recombination analysis of the two types of S-layer glycoproteins separately showed that both the $H$. gibbonsii clade and the $H$. volcanii clade underwent at least three recombination events each (Figures S2 and S3). 


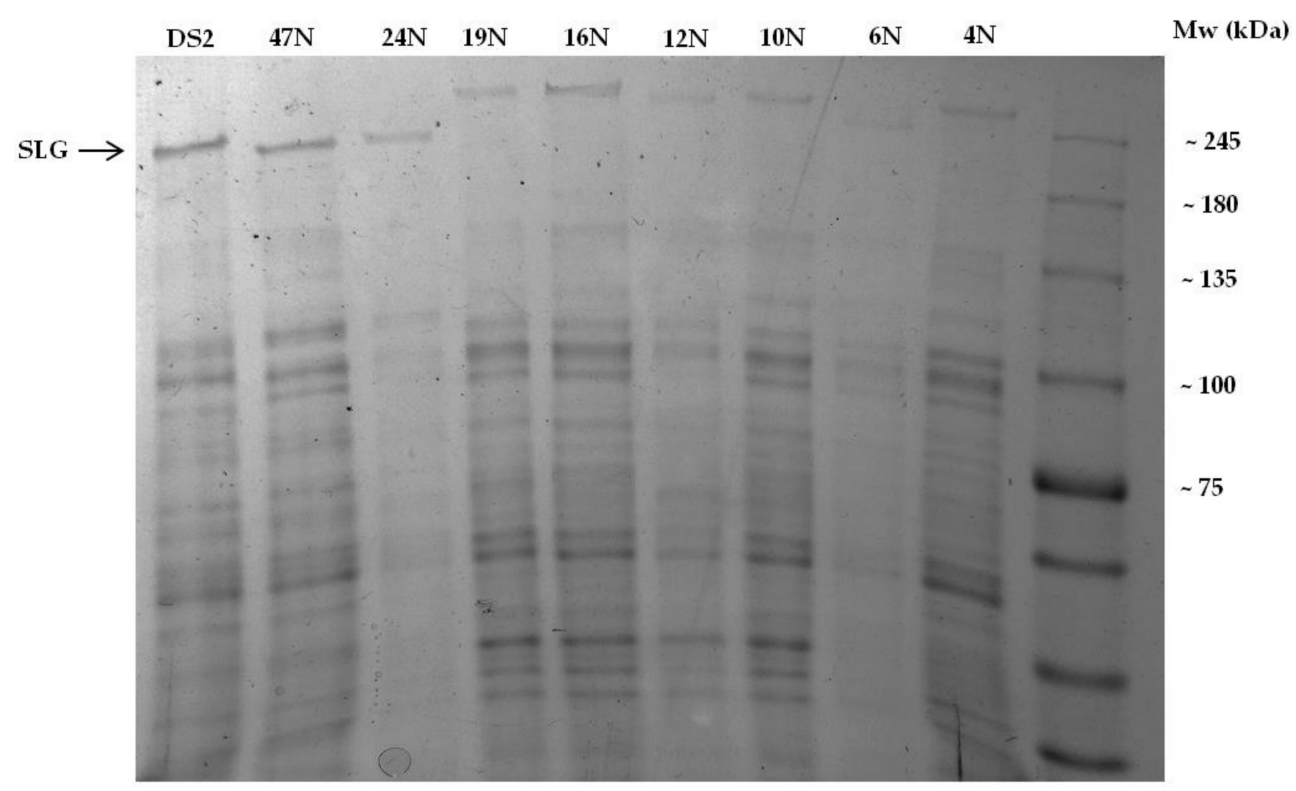

Figure 3. SDS-PAGE gels of protein samples extracted from the isolates and $H$. volcanii. The putative S-layer glycoprotein of $48 \mathrm{~N}$ is identical to that of $47 \mathrm{~N}$ (Figure S7).

\subsection{The Composition of Genes in N-Glycosylation Pathway Clusters Varies in the Isolates}

The isolates collected along Israel's Mediterranean coastline were sequenced and glycosylation gene clusters were identified in BLASTX searches [57]. In Archaea, the gene encoding the oligosaccharyltransferase AglB is almost universally detected and, in many cases, is found as part of a cluster of putative $\mathrm{N}$-glycosylation genes [22]. $\mathrm{H}$. volcanii contains the most studied and best-understood glycosylation pathway in Archaea. Based on what is known in H. volcanii [20], glycosylation clusters in the isolates were defined as including those genes between the aglB and $a g l J$ homologs (encoding the glycosyltransferase responsible for adding the first sugar of the $N$-linked pentasaccharide [58]). The aglJ gene was chosen as the border of the glycosylation cluster since it is the last gene in the $H$. volcanii glycosylation cluster and since $a g l J$ homologs were present in all the isolate clusters. Indeed, no ORFs with sequence similarity to any known glycosylation protein were observed upstream to aglJ in any of the isolate genomes.

As seen in Figure 2, most isolate glycosylation gene clusters (six out of nine) were found to be identical to that of $H$. gibbonsii, with only $16 \mathrm{~N}$ missing two glycosylation genes. Two other isolates, $47 \mathrm{~N}$ and $48 \mathrm{~N}$, are similar to the $H$. volcanii and putative $H$. denitrificans glycosylation gene clusters (the two species contain homologous genes in the same order and orientation, other than two transposable element insertions found in the $H$. volcanii cluster). The glycosylation gene cluster in isolate $24 \mathrm{~N}$ is similar to that in $H$. lucentense, with these genomes sharing more homologous genes with $H$. volcanii and $H$. denitrificans than with $H$. gibbonsii.

Even though the isolates belonging to the $\mathrm{H}$. gibbonsii clade share a similar glycosylation gene cluster with $H$. gibbonsii, they group separately in terms of their rpoB1 phylogeny (Figure 1). Likewise, $24 \mathrm{~N}$ has a glycosylation gene cluster similar to that of $H$. lucentense, yet groups closer to $H$. volcanii in the evolutionary analysis than did isolates $47 \mathrm{~N}$ and $48 \mathrm{~N}$, which group closer to H. lucentense, even though their glycosylation gene cluster is similar to that of $H$. volcanii (Figure 1).

Our results indicate that isolates and species that are similar in their glycosylation gene cluster pattern also share a type of S-layer glycoprotein. H. gibbonsii and the isolates that belong to the H. gibbonsii clade all express the same type of S-layer glycoprotein and share highly similar glycosylation gene clusters. Isolates $47 \mathrm{~N}$ and $48 \mathrm{~N}$ present glycosylation gene clusters similar to that of $H$. volcanii and share the type of S-layer glycoprotein. Although $24 \mathrm{~N}$ and $\mathrm{H}$. lucentense do not contain a glycosylation gene cluster identical to that $H$. volcanii, they do share homologous glycosyltransferases and other glycosylation-related genes, 
as well clustering on the rpoB1 tree (Figure 1). This implies that within these related lineages, major glycosylation gene clusters have been mostly vertically inherited, despite the fact that glycosylation genes in Haloferax have been shown to be frequently horizontally transferred [22].

\subsection{The Glycosyltransferase Gene aglJ Is Relatively Conserved}

The gene encoding glycosyltransferase AglJ, which is located on the opposite end of that encoding $\mathrm{AglB}$ in the H. volcanii glycosylation gene cluster, has homologs in the genomes of all of the isolates and the related species examined. AglJ adds the first sugar of the $N$-linked pentasaccharide decorating the $H$. volcanii S-layer glycoprotein [46] and should therefore be sugar-specific. Overall, the phylogenetic tree of aglJ (Figure 4a) resembles the tree constructed from the conserved gene rpoB1 (Figure 1), with the only difference a switching of position between $H$. volcanii and $H$. lucentense, likely reflecting gene transfer within this group of closely related organisms. We analyzed the $a g l J$ nucleotide sequence for within-gene recombination events and only one such event was found in all six sequences from the $H$. volcanii clade, where the recombined sequence originated in the $H$. gibbonsii clade (Figure S4). Thus, aglJ shows a predominantly vertical phylogenetic signal, yet even in this gene there is evidence of exchange between lineages.

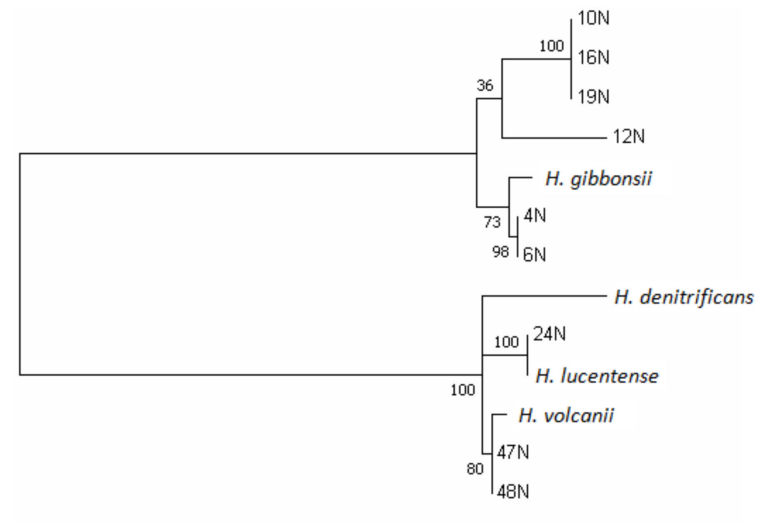

0.020

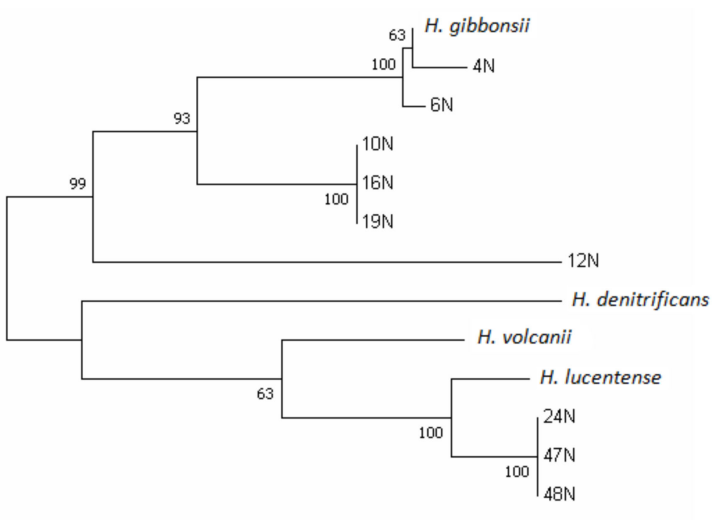

(b)

(a)

Figure 4. Cont. 


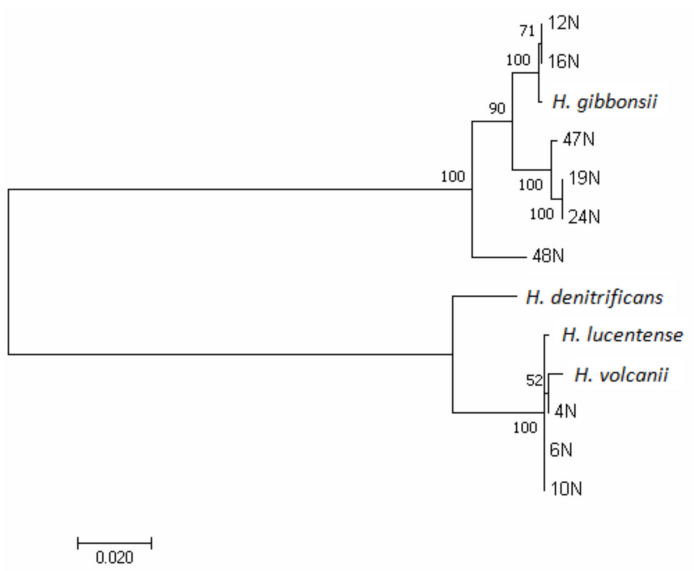

(c)

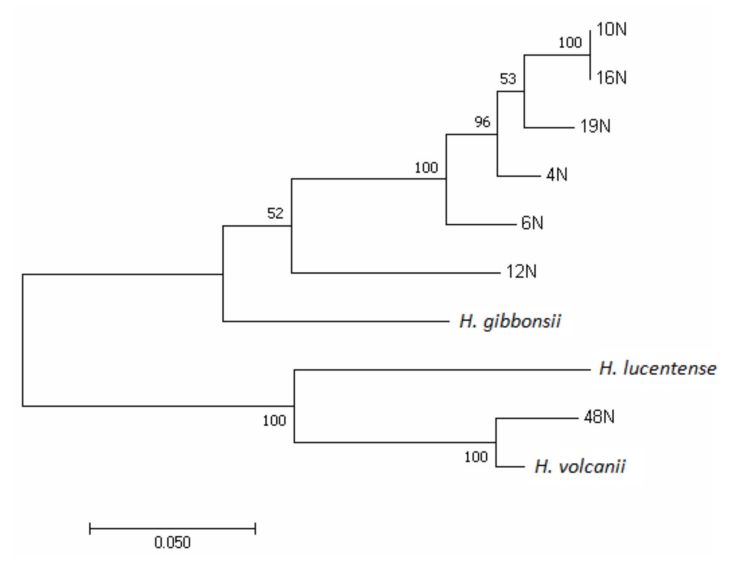

(d)

Figure 4. Molecular phylogenetic analysis by Maximum Likelihood method of genes related to glycosylation. The evolutionary history of trees $(\mathbf{a}, \mathbf{b}, \mathbf{d})$ were inferred by using the Maximum Likelihood method based on the Tamura-Nei model [31]. The percentage of trees in which the associated taxa clustered together is shown next to the branches. The unrooted trees are drawn to scale, with branch lengths measured in the number of substitutions per site. Evolutionary analyses were conducted in MEGA7 [30]. (a) Molecular phylogenetic analysis by Maximum Likelihood method of glycosyltransferase-encoding aglJ gene. The tree with the highest log likelihood (-2139.14) is shown. A discrete Gamma distribution was used to model evolutionary rate differences among sites ( 5 categories (+G, optimized shape parameter $=0.1945))$. The rate variation model allowed for some sites to be evolutionarily invariable $((+\mathrm{I}), 41.18 \%$ sites). The analysis involved 13 nucleotide sequences. Codon positions included were $1 \mathrm{st}+2 \mathrm{nd}+3 \mathrm{rd}$. All positions containing gaps and missing data were eliminated. A total of 901 positions were in the final dataset. (b) Molecular phylogenetic analysis by Maximum Likelihood method of mannosyltransferase-encoding aglD. The tree with the highest log likelihood (-3615.77) is shown. A discrete Gamma distribution was used to model evolutionary rate differences among sites $(5$ categories $(+G$, optimized shape parameter $=$ $0.1525))$. The rate variation model allowed for some sites to be evolutionarily invariable ((+I), 53.21\% sites). The analysis involved 13 nucleotide sequences. Codon positions included were $1 \mathrm{st}+2 \mathrm{nd}+3 \mathrm{rd}$. All positions containing gaps and missing data were eliminated. A total of 1875 positions were in the final dataset. (c) Molecular phylogenetic analysis by Maximum Likelihood method of the oligosaccharyltransferase AglB. The evolutionary history was inferred by using the Maximum Likelihood method based on the JTT matrix-based model [32]. The tree with the highest log likelihood (-4643.58) is shown. A discrete Gamma distribution was used to model evolutionary rate differences among sites $(5$ categories $(+\mathrm{G}$, parameter $=$ 200.0000)). The rate variation model allowed for some sites to be evolutionarily invariable $((+\mathrm{I}), 33.98 \%$ sites). The analysis involved 13 amino acid sequences. All positions containing gaps and missing data were eliminated. A total of 1040 positions were in the final dataset. (d) Molecular phylogenetic analysis by Maximum Likelihood method of the glycosyltransferase-encoding agl6. The tree with the highest log likelihood (-4223.78) is shown. A discrete Gamma distribution was used to model evolutionary rate differences among sites ( 5 categories $(+G$, optimized shape parameter $=0.9222)$ ). The rate variation model allowed for some sites to be evolutionarily invariable ((+I), 52.30\% sites). The analysis involved 10 nucleotide sequences. Codon positions included were $1 \mathrm{st}+2 \mathrm{nd}+3 \mathrm{rd}$. All positions containing gaps and missing data were eliminated. A total of 1242 positions were in the final dataset.

3.5. Phylogeny of the Mannosyltransferase-Encoding aglD Gene Is Similar to aglJ in the H. gibbonsii Clade but Not in the H. volcanii-Related Isolates

The final sugar of the $N$-linked pentasaccharide decorating the H. volcanii S-layer glycoprotein is mannose, which is added to a dolichol phosphate carrier on the cytoplasmic face of the membrane by the glycosyltransferase AgID [11]. Contrary to other genes whose products participate in the assembly and attachment of the pentasaccharide to selected Asn residues of $N$-glycosylated proteins in $H$. volcanii, 
aglD is not located within the major glycosylation cluster and generally has higher $G+C$ content than the rest of the genome (Table S2). Evolutionary analysis of aglD (Figure $4 \mathrm{~b}$ ) revealed that within the $H$. gibbonsii clade, the grouping was as observed for aglJ. However, in the H. volcanii clade, this was not the case. Here, isolate $24 \mathrm{~N}$ grouped closer to isolates $48 \mathrm{~N}$ and $47 \mathrm{~N}$, while $H$. volcanii occupied a more basal position than that observed in the aglJ and rpoB1 trees. Thus, the location of a gene within or outside the glycosylation gene cluster does not predict its evolutionary history, which is not surprising as most transferred genes in haloarchaea are integrated into the recipient genome by way of homologous recombination [51]. Analysis of the aglD nucleotide sequence for within-gene recombination events revealed only one such event, which was found in H. volcanii, coming from within the H. volcanii clade (Figure S5).

\subsection{The Gene Encoding AglB Most Likely Underwent Lateral Gene Transfer in Haloferax Species}

AglB orthologues from different haloarchaea were shown to be able to functionally complement the $H$. volcanii enzyme and successfully transfer the tetrasaccharide precursor of the $N$-linked pentasaccharide decorating the $H$. volcanii S-layer glycoprotein from the dolichol phosphate carrier to target asparagine residues [59] and inter-species complementation was also successfully shown in methanogens [60]. This implies considerable substrate flexibility, which can theoretically allow an aglB homolog acquired by horizontal gene transfer (HGT) to replace an ancestral orthologue, in a process known as xenologous gene displacement [61] — the most frequent outcome of HGT in haloarchaea [51]. The phylogenetic tree constructed from the AglB protein sequence (Figure 4c) differs significantly from the phylogeny of the more conserved rpoB1 shown in Figure 1. In contrast to rpoB1, the AglB tree forms two main groups. Moreover, the branching of the clusters and species branching as sister taxa in the AglB tree differs from the rpoB1 tree, implying HGT. The gene encoding AglB is almost universally detected [22], yet there is substantial variation in the composition of aglB-proximal glycosylation gene clusters in the different Haloferax strains and species, even in those closely related, possibly also reflecting HGT. The aglB-based $N$-glycosylation pathways have been shown to have an active role in cell-cell interactions and quite possibly cell recognition and to be important in haloarchaeal mating, as well as in other S-layer-related functions [62].

Analysis of the $a g l B$ nucleotide sequence for within-gene recombination events detected two events within the H. gibbonsii clade (Figure S6), one of which involves a lineage outside the H. gibbonsii clade. These data further support a history of frequent transfer for this gene family, likely aided by its functional flexibility.

\subsection{Alternative Glycosylation Clusters in Isolates and Related Haloferax Species}

It has been shown that $H$. volcanii responds to changes in environmental salinity by modulating the $\mathrm{N}$-linked glycans decorating the S-layer glycoprotein [6], with a second $\mathrm{N}$-glycosylation pathway being recruited in cells grown at lower salt concentrations [19]. Expression of these alternative glycosylation pathway genes results in a glycan chain that is different in composition than that produced by the main glycosylation pathway. The alternative glycosylation pathway in $H$. volcanii is composed of genes agl5-agl15 which have been shown to participate in the generation of the low-salt tetrasaccharide [21]. Using BLASTX [57], we found that most of the genes comprising the alternative pathway in H. volcanii are absent in the isolates. We compared putative alternative glycosylation clusters in the Haloferax genomes described above, based on the presence of the hallmark gene agl6 [21], which is present in all isolates except $24 \mathrm{~N}$ and $47 \mathrm{~N}$. From preliminary analysis we discovered that in all the isolate clusters there was an adjacent pilA2 gene downstream to agl6. PilA2 was conserved in all of the isolates, including $24 \mathrm{~N}$ and $47 \mathrm{~N}$, which upon further examination also had multiple glycosylation and flippase-related genes adjacent to pilA2, as in the rest of the isolates. In contrast to the major glycosylation pathway (Figure 2), the alternative glycosylation clusters were highly variable across the different genomes (Figure 5). 


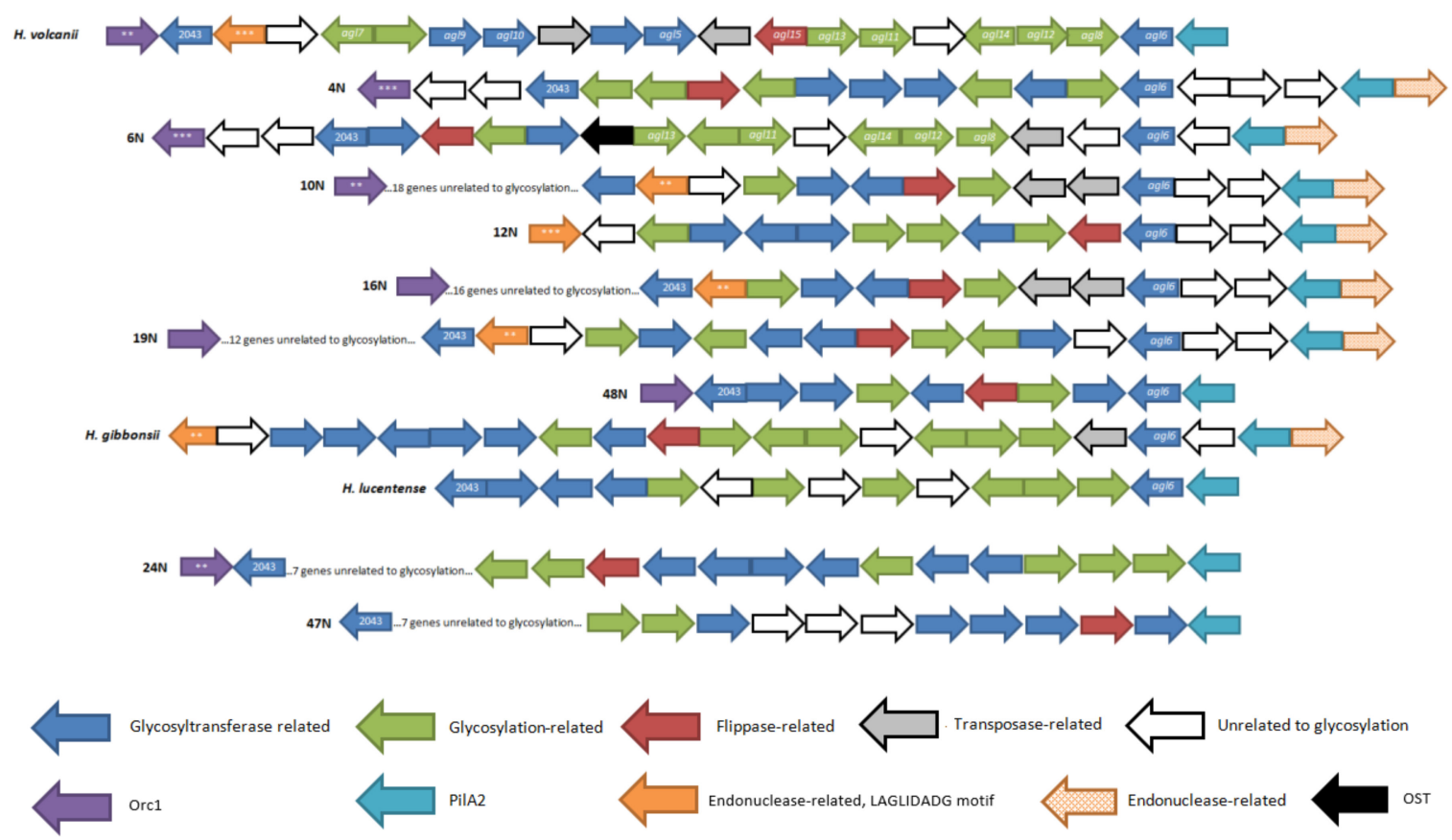

Figure 5. Schematic presentation of the agl6-based glycosylation gene clusters in four different Haloferax strains and the nine Haloferax isolates. The sizes of the genes are arbitrary. Asterisks indicate homology. Glycotransferases marked 2043 are homologs to HVO_2043, which is an uncharacterized gene adjacent to the alternative glycosylation gene pathway in $H$. volcanii. The legend describes the function assigned to each color used in the scheme. Protein function prediction was performed using HHpred [35]. Based on Figure 2 from Ref. [22].

It has been shown that $H$. volcanii responds to changes in environmental salinity by modulating the $\mathrm{N}$-linked glycans decorating the S-layer glycoprotein [6], with a second $\mathrm{N}$-glycosylation pathway being recruited in cells grown at lower salt concentrations [19]. Expression of these alternative glycosylation pathway genes results in a glycan chain that is different in composition than that produced by the main glycosylation pathway. The alternative glycosylation pathway in $\mathrm{H}$. volcanii is composed of genes agl5 - agl15 which have been shown to participate in the generation of the low-salt tetrasaccharide [21]. Using BLASTX [57], we found that most of the genes comprising the alternative pathway in $H$. volcanii are absent in the isolates. We compared putative alternative glycosylation clusters in the Haloferax genomes described above, based on the presence of the hallmark gene agl6 [21], which is present in all isolates except $24 \mathrm{~N}$ and $47 \mathrm{~N}$. From preliminary analysis we discovered that in all the isolate clusters there was an adjacent pilA2 gene downstream to agl6. PilA2 was conserved in all of the isolates, including $24 \mathrm{~N}$ and $47 \mathrm{~N}$, which upon further examination also had multiple glycosylation and flippase-related genes adjacent to pilA2, as in the rest of the isolates. In contrast to the major glycosylation pathway (Figure 2), the alternative glycosylation clusters were highly variable across the different genomes (Figure 5).

Although isolate $6 \mathrm{~N}$ putatively encodes a major glycosylation pathway homologous to that predicted in $\mathrm{H}$. gibbonsii, examination of the alternative pathway revealed that glycosylation genes from this isolate are more related to their $H$. volcanii counterparts. Most of the isolates also have an Orc1/CDC6-encoding gene, usually involved in origin recognition during replication initiation, indicating that these genes and their neighboring clusters could originate from replicating mobile elements, such as plasmids. Also, most isolates encode a putative glycosyltransferase which is homologous to an uncharacterized gene (HVO_2043) adjacent to the alternative glycosylation pathway gene cluster in H. volcanii. 
Isolates from the H. gibbonsii clade and H. volcanii also share a gene encoding a free-standing endonuclease with a LAGLIDADG motif family 2 motif (pfam03161). Indeed, its flanking DNA does not have significant similarity to any protein-coding gene, confirmed by a sensitive BLASTX [57] search. Such homing endonuclease-encoding genes tend to be found in introns and inteins within the open reading frames of other genes. However, free standing homing endonuclease were previously described, mostly in bacteriophages [63,64]. Isolates $24 \mathrm{~N}$ and $47 \mathrm{~N}$ do not have agl6 homologs, however they do contain type IV pilin homologs with adjacent glycosylation-related genes, as in the other clusters.

Phylogenetic analysis of the glycosyltransferase-encoding agl6 gene and its homologs in the isolates and isolate-related species revealed a different tree from the conserved rpoB1 tree as seen in Figure $4 \mathrm{~d}$. The agl6 tree still has two main clusters: the $H$. volcanii clade and the $H$. gibbonsii clade. However, the $H$. gibbonsii clade, in contrast to the $H$. volcanii clade, differs notably from the conserved rpoB1 phylogeny. H. gibbonsii diverges from isolates $4 \mathrm{~N}$ and $6 \mathrm{~N}$ contrary to the rpoB1 tree where they cluster together.

\section{Discussion}

Here, we show that even a population of strains isolated from two sampling sites less than $40 \mathrm{~km}$ apart can present considerable diversity in terms of cell surface biology and the genes involved. Our data demonstrate that genes within a clade of S-layer glycoproteins and $\mathrm{N}$-glycosylation genes can be conserved and show traces of recombination of some of those genes that mostly involve other members of the same clade. Such small scale recombination events have been shown to be common in halophilic archaea, especially within lineages [51]. This pattern of preferred recombination within lineages that results in diversification is in agreement with previous work showing that biased HGT can contribute to speciation processes as much as vertical descent. Similar observations have been also been made in bacteria [65-67].

Viruses may be one of the key drivers of within-species genome diversity in prokaryotes and this diversity often takes the form of genomic islands that contain genes present in a only small subset of strains that directly affect host-virus interactions [68]. In cyanobacteria, genomic islands encode surface factors that confer susceptibility or resistance to different bacteriophages [69]. In the haloarchaeon Haloquadratum walsbyi DSM 16790, two different genomic islands encode glycosyltransferases and S-layer glycoproteins [70]. Thus, viruses may exert an influence that is comparable to host immune system, producing not just different surface types, analogous to serotypes in bacterial pathogens but also a mechanism of switching the from one surface type to another as often seen in human pathogens and commensals [71,72].

In contrast to the major glycosylation clusters, alternative glycosylation clusters appear highly variable in gene content, even within the two Haloferax clades. Curiously, that cluster has a $\mathrm{G}+\mathrm{C}$ content of $52 \%$, much lower than any of the Haloferax genomes (Table 1), which is typical to mobile genetic elements that tend to have lower $G+C$ than their hosts [73]. Furthermore, many of these clusters have an orc1 gene, implying that they are derived from self-replicating mobile elements such as plasmids. The high level of variation in these clusters may give rise to different glycosylation patterns. Given that variation of the cell surface, such as a change of S-layer glycoprotein glycosylation pattern, could help achieve resistance against viral elements that bind to sugar receptors, such alternative clusters could provide a form of anti-viral defense, if expressed when cells become infected. Indeed, the alternative glycosylation cluster of $H$. volcanii is expressed under low salt conditions, which also induce expression of CRISPR, a veritable anti-viral defense, in H. mediterranei [74]. Thus, low-salt exposure for halophiles could induce similar envelope stress as associated with virus contact or entry, a stress that is thought to induce a CRISPR-Cas-mediated defense in bacteria [75]. Curiously, under low salt conditions, both wild type and $\triangle a g l B H$. volcanii cells become non-motile and form microcolonies [3], perhaps adapting a structure that is less sensitive to viral pressure, or less conducive for viral spread. 
The pilin gene adjacent to the alternative glycosylation locus in $H$. volcanii-known as pilA2-has a G + C content of $58.7 \%$, which is markedly lower than the genomic average, yet much higher than that of the glycosylation locus (see above). Interestingly, PilA2, which is one of the most highly expressed pilins in $H$. volcanii is highly $N$-glycosylated by AglB under optimal salt conditions [3] but whether under low salt, when AglB-mediated glycosylation is highly reduced, it undergoes glycosylation by the alternative pathway, remains to be determined.

Notably, most alternative glycosylation clusters in our isolates also contain free-standing homing endonuclease genes (i.e., homing endonucleases that are not located within an intron or an intein). Such enzymes typically recognize a highly specific target site over 20 bases long that appears only once in a typical archaeal genome and once they invade that site, the genome becomes immune to further cleavage [76]. This raises an intriguing possibility, namely that parts of these islands can sometimes be transferred via gene conversion, where the break is initiated by the homing endonuclease. Previous work has shown that homing in Haloferax can result in gene conversion events larger than $60 \mathrm{~kb}$ [77]. Thus, in principle, the whole island could be transferred in this fashion, when a target site exists in the recipient. Thus far, such free-standing homing endonucleases have mostly been observed in bacteriophages, where they cut the DNA of specific competing phages during co-infection [64], a process that can lead either to repair (and thereby invasion of the other phage by homing) or to the degradation of the viral DNA. Whether these endonucleases in haloarchaeal genomes can also provide resistance against viruses or other mobile genetic elements requires further study.

\section{Conclusions}

Here, we describe a new type of S-layer glycoprotein found in multiple Haloferax strains and provide evidence for within- and between-lineage gene transfer in the major and alternative glycosylation clusters in Haloferax that may result in situations where no two isolates present an identical surface profile. Such within-niche variation is expected to enhance the resistance of the Haloferax meta-population to viral pressures and may generate patterns of mating preference.

Supplementary Materials: The following are available online at http://www.mdpi.com/2073-4425/9/3/172/s1, Figure S1: Recombination events in the rpoB1 sequence, Figure S2: Recombination events in the SLG sequence of the $H$. gibbonsii clade, Figure S3: Recombination events in the SLG sequence of the $H$. volcanii clade, Figure S4: Recombination events in the aglJ sequence, Figure S5: Recombination events in the aglD sequence, Figure S6: Recombination events in the aglB sequence, Figure S7: SDS-PAGE gel of the isolates and H. volcanii DS2, Figure S8: Sequence alignment of the homing endonuclease with the LAGLIDAG motif seen in the alternative glycosylation pathway, Table S1: Matrix of average nucleotide identity (ANI) between the isolates, H. volcanii, H. gibbonsii, $H$. lucentense and H. denitrificans, Table S2: GC content of all genes mentioned before in the isolates and the related Haloferax species.

Acknowledgments: Research was funded by grants to U.G., J.P.G. and R.T.P. from the Binational Science Foundation (BSF, grants 2013061) and a BSF grant to U.G. (2016671) and an NSF grant (NSF/MCB 1716046) to J.P.G. and R.T.P., within the BSF-NSF joint research program. J.E. was supported by grants from the Israel Science Foundation (ISF) (grant 109/16) and the ISF-NSFC joint research program (grant 2193/16).

Author Contributions: U.G. and Y.S. conceived the study, U.G. and Y.S. designed experiments, U.G., Y.S., J.P.G. and S.M.S. analyzed data, Y.S. performed experiments, R.T.P. and J.P.G. supervised research, Y.S., U.G. and J.E. wrote the manuscript. All authors read and commented on the manuscript.

Conflicts of Interest: The authors declare that the research was conducted in the absence of any commercial or financial relationships that could be construed as a potential conflict of interest.

\section{References}

1. Akca, E.; Claus, H.; Schultz, N.; Karbach, G.; Schlott, B.; Debaerdemaeker, T.; Declercq, J.-P.; König, H. Genes and derived amino acid sequences of S-layer proteins from mesophilic, thermophilic, and extremely thermophilic methanococci. Extremophiles 2002, 6, 351-358. [CrossRef] [PubMed]

2. Tripepi, M.; You, J.; Temel, S.; Önder, Ö.; Brisson, D.; Pohlschröder, M. N-glycosylation of Haloferax volcanii flagellins requires known Agl proteins and is essential for biosynthesis of stable flagella. J. Bacteriol. 2012, 194, 4876-4887. [CrossRef] [PubMed] 
3. Esquivel, R.N.; Schulze, S.; Xu, R.; Hippler, M.; Pohlschroder, M. Identification of Haloferax volcanii Pilin $\mathrm{N}$-glycans with diverse roles in pilus biosynthesis, adhesion, and microcolony formation. J. Biol. Chem. 2016, 291, 10602-10614. [CrossRef] [PubMed]

4. Schwarz, F.; Aebi, M. Mechanisms and principles of N-linked protein glycosylation. Curr. Opin. Struct. Biol. 2011, 21, 576-582. [CrossRef] [PubMed]

5. Eichler, J.; Arbiv, A.; Cohen-Rosenzweig, C.; Kaminski, L.; Kandiba, L.; Konrad, Z. N-glycosylation in Haloferax volcanii: Adjusting the sweetness. Front. Microbiol. 2013, 4, 403. [CrossRef] [PubMed]

6. Guan, Z.; Naparstek, S.; Calo, D.; Eichler, J. Protein glycosylation as an adaptive response in Archaea: growth at different salt concentrations leads to alterations in Haloferax volcanii S-layer glycoprotein $N$-glycosylation. Environ. Microbiol. 2012, 14, 743-753. [CrossRef] [PubMed]

7. Abu-Qarn, M.; Giordano, A.; Battaglia, F.; Trauner, A.; Hitchen, P.G.; Morris, H.R.; Dell, A.; Eichler, J. Identification of AglE, a second glycosyltransferase involved in N-glycosylation of the Haloferax volcanii S-layer glycoprotein. J. Bacteriol. 2008, 190, 3140-3146. [CrossRef] [PubMed]

8. Yurist-Doutsch, S.; Abu-Qarn, M.; Battaglia, F.; Morris, H.R.; Hitchen, P.G.; Dell, A.; Eichler, J. aglF, aglG and aglI, novel members of a gene island involved in the $\mathrm{N}$-glycosylation of the Haloferax volcanii S-layer glycoprotein. Mol. Microbiol. 2008, 69, 1234-1245. [CrossRef] [PubMed]

9. Guan, Z.; Naparstek, S.; Kaminski, L.; Konrad, Z.; Eichler, J. Distinct glycan-charged phosphodolichol carriers are required for the assembly of the pentasaccharide $N$-linked to the Haloferax volcanii S-layer glycoprotein. Mol. Microbiol. 2010, 78, 1294-1303. [CrossRef] [PubMed]

10. Kaminski, L.; Eichler, J. Identification of residues important for the activity of Haloferax volcanii AglD, a component of the archaeal N-glycosylation pathway. Archaea 2010, 2010, 315108. [CrossRef] [PubMed]

11. Abu-Qarn, M.; Yurist-Doutsch, S.; Giordano, A.; Trauner, A.; Morris, H.R.; Hitchen, P.; Medalia, O.; Dell, A.; Eichler, J. Haloferax volcanii AglB and AgID are involved in N-glycosylation of the S-layer glycoprotein and proper assembly of the surface Layer. J. Mol. Biol. 2007, 374, 1224-1236. [CrossRef] [PubMed]

12. Kandiba, L.; Lin, C.-W.; Aebi, M.; Eichler, J.; Guerardel, Y. Structural characterization of the N-linked pentasaccharide decorating glycoproteins of the halophilic archaeon Haloferax volcanii. Glycobiology 2016, 26, 745-756. [CrossRef] [PubMed]

13. Plavner, N.; Eichler, J. Defining the topology of the $N$-glycosylation pathway in the halophilic archaeon Haloferax volcanii. J. Bacteriol. 2008, 190, 8045-8052. [CrossRef] [PubMed]

14. Calo, D.; Guan, Z.; Naparstek, S.; Eichler, J. Different routes to the same ending: Comparing the $N$-glycosylation processes of Haloferax volcanii and Haloarcula marismortui, two halophilic archaea from the Dead Sea. Mol. Microbiol. 2011, 81, 1166-1177. [CrossRef] [PubMed]

15. Cohen-Rosenzweig, C.; Yurist-Doutsch, S.; Eichler, J. AglS, a novel component of the Haloferax volcanii $N$-glycosylation pathway, is a dolichol phosphate-mannose mannosyltransferase. J. Bacteriol. 2012, 194, 6909-6916. [CrossRef] [PubMed]

16. Kaminski, L.; Guan, Z.; Abu-Qarn, M.; Konrad, Z.; Eichler, J. AglR is required for addition of the final mannose residue of the $N$-linked glycan decorating the Haloferax volcanii S-layer glycoprotein. Biochim. Biophys. Acta-Gen. Subj. 2012, 1820, 1664-1670. [CrossRef] [PubMed]

17. Yurist-Doutsch, S.; Magidovich, H.; Ventura, V.V.; Hitchen, P.G.; Dell, A.; Eichler, J. N-glycosylation in Archaea: On the coordinated actions of Haloferax volcanii AglF and AglM. Mol. Microbiol. 2010, 75, 1047-1058. [CrossRef] [PubMed]

18. Arbiv, A.; Yurist-Doutsch, S.; Guan, Z.; Eichler, J.; Hashimoto, W. AglQ is a novel component of the Haloferax volcanii N-glycosylation pathway. PLoS ONE 2013, 8, e81782. [CrossRef] [PubMed]

19. Magidovich, H.; Yurist-Doutsch, S.; Konrad, Z.; Ventura, V.V.; Dell, A.; Hitchen, P.G.; Eichler, J. AglP is a $S$-adenosyl-L-methionine-dependent methyltransferase that participates in the $N$-glycosylation pathway of Haloferax volcanii. Mol. Microbiol. 2010, 76, 190-199. [CrossRef] [PubMed]

20. Yurist-Doutsch, S.; Eichler, J. Manual annotation, transcriptional analysis, and protein expression studies reveal novel genes in the agl cluster responsible for $N$-glycosylation in the halophilic archaeon Haloferax volcanii. J. Bacteriol. 2009, 191, 3068-3075. [CrossRef] [PubMed]

21. Kaminski, L.; Guan, Z.; Yurist-Doutsch, S.; Eichler, J. Two distinct N-glycosylation pathways process the Haloferax volcanii S-layer glycoprotein upon changes in environmental salinity. MBio 2013, 4, 1-9. [CrossRef] [PubMed] 
22. Kaminski, L.; Lurie-Weinberger, M.N.; Allers, T.; Gophna, U.; Eichler, J. Phylogenetic- and genome-derived insight into the evolution of $N$-glycosylation in Archaea. Mol. Phylogenet. Evol. 2013, 68, 327-339. [CrossRef] [PubMed]

23. Youssef, N.H.; Ashlock-Savage, K.N.; Elshahed, M.S. Phylogenetic diversities and community structure of members of the extremely halophilic Archaea (order Halobacteriales) in multiple saline sediment habitats. Appl. Environ. Microbiol. 2012, 78, 1332-1344. [CrossRef] [PubMed]

24. Martin, M. Cutadapt removes adapter sequences from high-throughput sequencing reads. EMBnet J. 2011, 17, 10. [CrossRef]

25. Bankevich, A.; Nurk, S.; Antipov, D.; Gurevich, A.A.; Dvorkin, M.; Kulikov, A.S.; Lesin, V.M.; Nikolenko, S.I.; Pham, S.; Prjibelski, A.D.; et al. SPAdes: A new genome assembly algorithm and its applications to single-cell sequencing. J. Comput. Biol. 2012, 19, 455-477. [CrossRef] [PubMed]

26. Gurevich, A.; Saveliev, V.; Vyahhi, N.; Tesler, G. QUAST: Quality assessment tool for genome assemblies. Bioinformatics 2013, 29, 1072-1075. [CrossRef] [PubMed]

27. Seemann, T. Prokka: Rapid prokaryotic genome annotation. Bioinformatics 2014, 30, 2068-2069. [CrossRef] [PubMed]

28. Kanehisa, M.; Sato, Y.; Kawashima, M.; Furumichi, M.; Tanabe, M. KEGG as a reference resource for gene and protein annotation. Nucleic Acids Res. 2016, 44, D457-D462. [CrossRef] [PubMed]

29. Katoh, K.; Standley, D.M. MAFFT multiple sequence alignment software version 7: Improvements in performance and usability. Mol. Biol. Evol. 2013, 30, 772-780. [CrossRef] [PubMed]

30. Tamura, K.; Stecher, G.; Peterson, D.; Filipski, A.; Kumar, S. MEGA6: Molecular evolutionary genetics analysis version 6.0. Mol. Biol. Evol. 2013, 30, 2725-2729. [CrossRef] [PubMed]

31. Tamura, K.; Nei, M. Estimation of the number of nucleotide substitutions in the control region of mitochondrial DNA in humans and chimpanzees. Mol. Biol. Evol. 1993, 10, 512-526. [PubMed]

32. Le, S.Q.; Gascuel, O. An improved general amino acid replacement matrix. Mol. Biol. Evol. 2008, 25, 1307-1320. [CrossRef] [PubMed]

33. Pearson, W.R. Effective protein sequence comparison. Methods Enzymol. 1996, 266, 227-258. [PubMed]

34. Pearson, W.R.; Lipman, D.J. Improved tools for biological sequence comparison. Proc. Natl. Acad. Sci. USA 1988, 85, 2444-2448. [CrossRef] [PubMed]

35. Zimmermann, L.; Stephens, A.; Nam, S.-Z.; Rau, D.; Kübler, J.; Lozajic, M.; Gabler, F.; Söding, J.; Lupas, A.N.; Alva, V. A completely reimplemented MPI bioinformatics toolkit with a new HHpred Server at its core. J. Mol. Biol. 2017. [CrossRef] [PubMed]

36. Martin, D.; Rybicki, E. RDP: Detection of recombination amongst aligned sequences. Bioinformatics 2000, 16, 562-563. [CrossRef] [PubMed]

37. Padidam, M.; Sawyer, S.; Fauquet, C.M. Possible emergence of new geminiviruses by frequent recombination. Virology 1999, 265, 218-225. [CrossRef] [PubMed]

38. Martin, D.P.; Posada, D.; Crandall, K.A.; Williamson, C. A modified bootscan algorithm for automated identification of recombinant sequences and recombination breakpoints. AIDS Res. Hum. Retrovir. 2005, 21, 98-102. [CrossRef] [PubMed]

39. Smith, J. Analyzing the mosaic structure of genes. J. Mol. Evol. 1992, 34, 126-129. [CrossRef] [PubMed]

40. Posada, D.; Crandall, K.A. Evaluation of methods for detecting recombination from DNA sequences: Computer simulations. Proc. Natl. Acad. Sci. USA 2001, 98, 13757-13762. [CrossRef] [PubMed]

41. Gibbs, M.J.; Armstrong, J.S.; Gibbs, A.J. Sister-scanning: A Monte Carlo procedure for assessing signals in recombinant sequences. Bioinformatics 2000, 16, 573-582. [CrossRef] [PubMed]

42. Boni, M.F.; Posada, D.; Feldman, M.W. An exact nonparametric method for inferring mosaic structure in sequence triplets. Genetics 2007, 176, 1035-1047. [CrossRef] [PubMed]

43. Martin, D.P.; Murrell, B.; Golden, M.; Khoosal, A.; Muhire, B. RDP4: Detection and analysis of recombination patterns in virus genomes. Virus Evol. 2015, 1. [CrossRef] [PubMed]

44. Rodriguez-R, L.M.; Konstantinidis, K.T. Bypassing cultivation to identify bacterial species culture-independent genomic approaches identify credibly distinct clusters, avoid cultivation bias, and provide true insights into microbial species. Microbe 2014, 9, 111-118.

45. Klappenbach, J.A.; Goris, J.; Vandamme, P.; Coenye, T.; Konstantinidis, K.T.; Tiedje, J.M. DNA-DNA hybridization values and their relationship to whole-genome sequence similarities. Int. J. Syst. Evol. Microbiol. 2007, 57, 81-91. [CrossRef] 
46. Allers, T.; Barak, S.; Liddell, S.; Wardell, K.; Mevarech, M. Improved strains and plasmid vectors for conditional overexpression of His-tagged proteins in Haloferax volcanii. Appl. Environ. Microbiol. 2010, 76, 1759-1769. [CrossRef] [PubMed]

47. He, F. Laemmli-SDS-PAGE. Bio-Protocol 2011, 1, 16. [CrossRef]

48. Walsh, D.A.; Bapteste, E.; Kamekura, M.; Doolittle, W.F. Evolution of the RNA Polymerase B' Subunit Gene $\left(r p o B^{\prime}\right)$ in Halobacteriales: a complementary molecular marker to the SSU rRNA Gene. Mol. Biol. Evol. 2004, 21, 2340-2351. [CrossRef] [PubMed]

49. Papke, R.T.; Koenig, J.E.; Rodríguez-Valera, F.; Doolittle, W.F. Frequent recombination in a saltern population of Halorubrum. Science 2004, 306, 1928-1929. [PubMed]

50. Papke, R.T.; Zhaxybayeva, O.; Feil, E.J.; Sommerfeld, K.; Muise, D.; Doolittle, W.F. Searching for species in haloarchaea. Proc. Natl. Acad. Sci. USA 2007, 104, 14092-14097. [CrossRef] [PubMed]

51. Williams, D.; Gogarten, J.P.; Papke, R.T. Quantifying homologous replacement of loci between haloarchaeal species. Genome Biol. Evol. 2012, 4, 1223-1244. [CrossRef] [PubMed]

52. Rodriguez-R, L.M.; Konstantinidis, K.T. The enveomics collection: A toolbox for specialized analyses of microbial genomes and metagenomes. Peer J. Prepr. 2016. [CrossRef]

53. Sumper, M.; Berg, E.; Mengele, R.; Strobel, I. Primary structure and glycosylation of the S-layer protein of Haloferax volcanii. J. Bacteriol. 1990, 172, 7111-7118. [CrossRef] [PubMed]

54. Jones, P.; Binns, D.; Chang, H.-Y.; Fraser, M.; Li, W.; McAnulla, C.; McWilliam, H.; Maslen, J.; Mitchell, A.; Nuka, G.; et al. InterProScan 5: Genome-scale protein function classification. Bioinformatics 2014, 30, 1236-1240. [CrossRef] [PubMed]

55. Altschul, S. F.; Gish, W.; Miller, W.; Myers, E. W.; Lipman, D. J. Basic local alignment search tool. J. Mol. Biol. 1990, 215, 403-410. [CrossRef]

56. Stothard, P. The sequence manipulation suite: JavaScript programs for analyzing and formatting protein and DNA sequences. Biotechniques 2000, 28, 1102-1104. [PubMed]

57. Gish, W.; States, D. J. Identification of protein coding regions by database similarity search. Nat. Genet. 1993, 3, 266-272. [CrossRef] [PubMed]

58. Kaminski, L.; Abu-Qarn, M.; Guan, Z.; Naparstek, S.; Ventura, V.V.; Raetz, C.R.H.; Hitchen, P.G.; Dell, A.; Eichler, J. AglJ adds the first sugar of the N-linked pentasaccharide decorating the Haloferax volcanii S-layer glycoprotein. J. Bacteriol. 2010, 192, 5572-5579. [CrossRef] [PubMed]

59. Cohen-Rosenzweig, C.; Guan, Z.; Shaanan, B.; Eichler, J. Substrate promiscuity: AglB, the archaeal oligosaccharyltransferase, can process a variety of lipid-linked glycans. Appl. Environ. Microbiol. 2014, 80, 486-496. [CrossRef] [PubMed]

60. Ding, Y.; Vrionis, H.A.; Schneider, J.; Berezuk, A.; Khursigara, C.M.; Jarrell, K.F. Complementation of an AglB Mutant of Methanococcus maripaludis with heterologous oligosaccharyltransferases. PLoS ONE 2016, 11, e0167611. [CrossRef] [PubMed]

61. Omelchenko, M.V.; Makarova, K.S.; Wolf, Y.I.; Rogozin, I.B.; Koonin, E.v. Evolution of mosaic operons by horizontal gene transfer and gene displacement in situ. Genome Biol. 2003, 4, R55. [CrossRef] [PubMed]

62. Eichler, J.; Koomey, M. Sweet new roles for protein glycosylation in prokaryotes. Trends Microbiol. 2017, 25, 662-672. [CrossRef] [PubMed]

63. Dassa, B.; London, N.; Stoddard, B.L.; Schueler-Furman, O.; Pietrokovski, S. Fractured genes: A novel genomic arrangement involving new split inteins and a new homing endonuclease family. Nucleic Acids Res. 2009, 37, 2560-2573. [CrossRef] [PubMed]

64. Belle, A.; Landthaler, M.; Shub, D.A. Intronless homing: Site-specific endonuclease SegF of bacteriophage T4 mediates localized marker exclusion analogous to homing endonucleases of group I introns. Genes Dev. 2002, 16, 351-362. [CrossRef] [PubMed]

65. Thane Papke, R.; Naor, A.; Gophna, U. Speciation in the shadow of recombination and lateral gene transfer. In Lateral Gene Transfer in Evolution; Springer: New York, NY, USA, 2013; pp. 275-289.

66. Andam, C.P.; Williams, D.; Gogarten, J.P. Biased gene transfer mimics patterns created through shared ancestry. Proc. Natl. Acad. Sci. USA 2010, 107, 10679-10684. [CrossRef] [PubMed]

67. Shapiro, B.J.; Friedman, J.; Cordero, O.X.; Preheim, S.P.; Timberlake, S.C.; Szabo, G.; Polz, M.F.; Alm, E.J. population genomics of early events in the ecological differentiation of bacteria. Science 2012, 336, 48-51. [CrossRef] [PubMed] 
68. Rodriguez-Valera, F.; Martin-Cuadrado, A.-B.; Rodriguez-Brito, B.; Pašić, L.; Thingstad, T.F.; Rohwer, F.; Mira, A. Explaining microbial population genomics through phage predation. Nat. Rev. Microbiol. 2009, 7, 828-836. [CrossRef] [PubMed]

69. Avrani, S.; Wurtzel, O.; Sharon, I.; Sorek, R.; Lindell, D. Genomic island variability facilitates Prochlorococcus-virus coexistence. Nature 2011, 474, 604-608. [CrossRef] [PubMed]

70. Cuadros-Orellana, S.; Martin-Cuadrado, A.-B.; Legault, B.; D’Auria, G.; Zhaxybayeva, O.; Papke, R.T.; Rodriguez-Valera, F. Genomic plasticity in prokaryotes: The case of the square haloarchaeon. ISME J. 2007, 1, 235-245. [CrossRef] [PubMed]

71. Croucher, N.J.; Kagedan, L.; Thompson, C.M.; Parkhill, J.; Bentley, S.D.; Finkelstein, J.A.; Lipsitch, M.; Hanage, W.P. Selective and genetic constraints on pneumococcal serotype switching. PLoS Genet. 2015, 11, e1005095. [CrossRef] [PubMed]

72. Taketani, M.; Donia, M.S.; Jacobson, A.N.; Lambris, J.D.; Fischbach, M.A. A phase-variable surface layer from the gut symbiont Bacteroides thetaiotaomicron. MBio 2015, 6, e01339-15. [CrossRef] [PubMed]

73. Daubin, V.; Lerat, E.; Perrière, G. The source of laterally transferred genes in bacterial genomes. Genome Biol. 2003, 4, R57. [CrossRef] [PubMed]

74. Mojica, F.J.M.; Juez, G.; Rodriguez-Valera, F. Transcription at different salinities of Haloferax mediterranei sequences adjacent to partially modified PstI sites. Mol. Microbiol. 1993, 9, 613-621. [CrossRef] [PubMed]

75. Perez-Rodriguez, R.; Haitjema, C.; Huang, Q.; Nam, K.H.; Bernardis, S.; Ke, A.; DeLisa, M.P. Envelope stress is a trigger of CRISPR RNA-mediated DNA silencing in Escherichia coli. Mol. Microbiol. 2011, 79, 584-599. [CrossRef] [PubMed]

76. Barzel, A.; Naor, A.; Privman, E.; Kupiec, M.; Gophna, U. Homing endonucleases residing within inteins: Evolutionary puzzles awaiting genetic solutions. Biochem. Soc. Trans. 2011, 39, 169-173. [CrossRef] [PubMed]

77. Naor, A.; Altman-Price, N.; Soucy, S.M.; Green, A.G.; Mitiagin, Y.; Turgeman-Grott, I.; Davidovich, N.; Gogarten, J.P.; Gophna, U. Impact of a homing intein on recombination frequency and organismal fitness. Proc. Natl. Acad. Sci. USA 2016, 113, E4654-E4661. [CrossRef] [PubMed] 